\title{
Códigos para el Análisis de Política Educativa Local en Chile: temas pendientes*
}

- Moyra Castro Paredes**

\section{Códigos para a análise da política de educação locais no Chile: questões pendentes Resumo}

0 artigo tenta mostrar a política educacional a partir de uma perspectiva do território e como ela tende a invisibilidade e complexidade nas instituições subnacionais, ou seja, os municípios e serviço de educação. Ele descreve brevemente a dinâmica da política nacional de educação relacionada com as reformas educacionais ocorridas no último quarto do século XX e caracteriza a sua aplicação no contexto subnacional. Os temas são distribuídos apenas para fins práticos nas áreas de financiamento, gestão, participação e convivência cidadã, regulamento e currículo. No final, apresenta algumas considerações para a política de educação municipal, seu potencial de apropriação e progressão nos governos locais.

Palavras-chave: Política de educação local. As políticas públicas de educação. Municipalização da educação. Desafios da política educacional no território.

\section{Resumen}

El artículo intenta significar la política educativa desde una visión de territorio y como ésta tiende a la invisibilidad y a la complejidad en las instituciones subnacionales, en concreto, los Municipios y sus servicios de educación. Para ello, describe brevemente la dinámica de la política educativa nacional vinculada a las reformas educativas acontecidas en el último cuarto del siglo XX y caracteriza su implementación en el contexto subnacional. Los temas están distribuidos sólo con fines prácticos en ámbitos de financiamiento, gestión, participación y conviavilidad, regulación y currículum. Al final, contempla algunas consideraciones ante la política educativa municipal, sus posibilidades apropiación y progresión en los gobiernos locales.

\footnotetext{
${ }^{*}$ Este artículo es parte del Proyecto PBCT-CONICYT PSD-60.

${ }^{* *}$ Dra. en Educación; Académica e Investigadora Asistente, Instituto de Investigación y Desarrollo Educacional de la Universidad de Talca. E-mail: mocastro@utalca.cl
} 
Palabras clave: Política educativa local. Política de educación pública. Municipalización educativa. Desafíos de la política educativa en el territorio.

\section{Codes for the Analysis of Local Education Policy in Chile. Pending Issues Abstract}

This article attempts to present an educational policy from a perspective of territory and how it tends to invisibility and complexity in sub-national institutions, namely the municipalities and educational department. It outlines briefly the dynamics of national education policy related to educational reforms occurring in the last quarter of the twentieth century and characterizes its implementation at the sub-national context. The topics are distributed only for practical purposes in areas of financing, management, participation and citizen coexistence, regulation and curriculum. Finally, at the end of the article, it provides some considerations to the municipal education policy, its potential ownership and progression in local government.

Keywords: Local education policy. Public education policies. Education municipalization. Challenges of educational policy in the territory.

\section{Introducción}

Para el caso de nuestro país, las políticas educacionales en Chile relacionadas con el territorio resurgieron en los años ochenta ${ }^{1}$, fundamentalmente asociadas a la descentralización de la educación, y ésta a su vez, integrada a un proceso más global del pais, de ordenamiento administrativo, fiscal y en esencia no político Ilamado Reforma Administrativa del Estado. Los argumentos tras estos procesos envolvían razones ideológicas y económicas. Por un lado, el desmantelamiento de la influencia estatal y de las autoridades políticas y, por otro, el advenimiento de la concepción neoliberal a fin de dotar de eficiencia y competitividad la prestación de servicios sociales. Dichas acciones se manifestaron entre 1974 y 1980 con la redefinición de la administración territorial, regionalización del país; ampliación de las competencias municipales, transferencia de la mayor parte de los servicios sociales, incluida la educación fiscal, a las municipalidades; y reserva de las funciones normativas, financieras y fiscalizadoras a las instancias centrales.

Bajo la perspectiva de territorio, la implementación de la política educativa parece ser menos explícita y puede decirse sin temor, menos consciente. Por ese motivo, el análisis acontece al interior de dos reformas educacionales que

\footnotetext{
${ }^{1}$ Los intentos de descentralización han sido una constante en la política educativa, basta revisar la Carta Fundamental de 1925 que continuó asignando obligaciones educacionales a las Municipalidades, en el Capitulo IX del Régimen Administrativo Interior. Descontando que desde tiempos coloniales, la incipiente instrucción privada y pública en Chile estuvo subordinada a las congregaciones religiosas y a la asamblea de la comunidad, es decir, inserta en diferentes jurisdicciones locales.
} 
coexisten hasta el día de hoy. Ambas ocurridas en el último cuarto del siglo XX, coinciden además, con igual períodos gubernamentales cruciales en Chile. El primero corresponde al régimen que por dieciséis años y medio gobernó de forma dictatorial y, el segundo con el retorno del régimen democrático.

\section{Política educativa en el territorio}

La definición de política educativa local genera ambigüedad y en cierta medida sólo se limita al nivel de implementación, de ejecución, no de diseño, a pesar de la concluyente disparidad de comunas en Chile en geografía, demografía, territorio y recursos. En educación, la matrícula promedio anual del año 2007 en 343 municipios es de 1.7 millones de estudiantes. En promedio cada municipio concentra un poco menos de 5.000 alumnos. La varianza es cuantiosa. "Así, la mediana es de casi dos mil 400 alumnos, el máximo es de 45 mil 200 y el mínimo de cinco. Asimismo, el 75 por ciento de las comunas tiene menos de 5 mil 600 estudiantes" (BEYER, 2009, p. 102). Las políticas educativas son diseñadas para un tipo de Escuela, para un tipo de territorio y manifiestan poca deferencia por la diversidad (MONTT et al., 2006). Tienden a la desterritorialización, se emprenden en forma homogénea sin domicilio particular (CORBETTA, 2009). Por eso no es tan fácil comprobar la existencia de la política educativa en el territorio, salvo dentro de márgenes de la excepción y no de la norma general.

Para revelar la política educativa local se estudian algunos informes sobre la descentralización de la educación en Chile y estudios de la gestión de la educación municipal ${ }^{2}$ que atienden a los principales ámbitos de la política educativa del proceso de municipalización. Los temas están clasificados sólo con fines prácticos en politicas de: financiamiento, gestión, participación y conviavilidad, regulación y currículum; sabiendo que en la realidad, todas pueden imbricarse y potenciarse mutuamente, dependiendo eso sí, más de los usos que del discurso en sí mismo. En otras palabras, la política no pasa solamente por disposiciones que afecten a un más o un menos, efectivamente ellas ayudan, pero existen bastantes ejemplos que no necesariamente armonizan con la norma, es más, inclusive contradicen el espiritu de la norma.

\section{Politicas de financiamiento}

La politica de financiamiento es un tema decisivo del sistema educativo. El régimen dictatorial impuso grandes secuelas: el desplome sistemático del presupuesto nacional para educación desde 1982 hasta 1990; la disminución de

\footnotetext{
${ }^{2}$ Ver Larrañaga (1995), Cominetti y Di Gropello (1998); Di Gropello (2004), González (2005a), Latorre y otros (1991), Serrano, Fernández y Pávez (2001), Chile (2002a, 2002b), Pávez (2004), Chile (2006); Chile (2007b); Chile (2008a).
} 
recursos públicos y la introducción del subsidio a la demanda para financiar la educación pública en todos sus niveles. En conjunto, produjo un deterioro del sistema educativo de difícil restitución.

Si bien "el Gobierno central proporciona un 90\% de la financiación de la enseñanza primaria y secundaria, aunque delega la responsabilidad de gestionar los servicios educativos a los municipios y a las escuelas gestionadas por el sector privado" (WINKLER, 2000, p. 50), lo cierto es que el subsidio desde el principio fue desindexado producto de la crisis económica de 1982 y porque no decir de su fuerte improvisación ${ }^{3}$. Su declinación se extiende en el transcurso de la década y repunta después de 1990 con el cambio gubernamental (CARNOY, 2005), garantizando el financiamiento de los reajustes salariales y la recuperación de su poder adquisitivo (OCDE; CHILE, 2004).

Por lo demás, se adjudica "como condición necesaria para su adecuado funcionamiento la existencia de un mercado educativo competitivo, con libertad de entrada y salida de oferentes y demandantes, debidamente informados de las características de la oferta educativa" (DONOSO; SCHMAL, 2002, p. 19). Sin embargo, su aplicación fue resueltamente alterada y persiste en la actualidad. Por consiguiente: i) los padres no reciben información apropiada respecto del rendimiento efectivo de los colegios ${ }^{4}$,ii) los establecimientos educacionales municipalizados no disponen de autonomía para su gestión; y iii) substancialmente, la administración municipal no se ocupa de la presión competitiva representada por la pérdida de matrícula porque su déficit es financiado por el gobierno central (COX, 2005).

Con respecto a la subvención, varía según la asistencia mensual, modalidad de educación y nivel de enseñanza, jornada escolar, factor de ruralidad y desempeño laboral, entre otras. En tanto la compensación de recursos para la población escolar más vulnerable fue débil y marginal, sólo hasta la promulgación de la Ley $n^{\circ} 20.284$ (CHILE, 2008b), estableciendo una subvención diferente para un segmento de la población escolar, "un 30\% adicional de recursos por estudiante (US \$ 38) perteneciente al segmento

\footnotetext{
3 A mitad del año 1980, el discurso ministerial sostenía que el proyecto de municipalización se iniciaría en 1982 como proceso piloto en algunas comunas representativas seleccionadas. Sin embargo, después de la copiosa promulgación de leyes sobre la materia fue evidente la intención de traspasar masiva y rápidamente a los municipios.

${ }^{4}$ A pesar del esfuerzo comunicacional la encuesta CEP de 2006 Evaluación de la calidad de la educación en Chile mostró que más del 40\% de los padres no conoce el SIMCE del colegio de su hijo y sólo el 11\% lo considera para elegir el colegio para sus hijos. La encuesta CIDE-Universidad Alberto Hurtado de 2006 Actores del sistema educativo reveló que el 21,2\% de los padres conoce el puntaje SIMCE del colegio de su hijo, mientras el 51,6\% desconoce o tiene poca información sobre los resultados del establecimiento. Además, los apoderados de centros municipalizados están más desinformados que los apoderados de centros particulares, estos últimos acceden con mayor facilidad a los puntajes de sus instituciones.
} 
más pobre, además de asignar ingresos complementarios a los establecimientos que tienen al menos el 15\% de población perteneciente a los segmentos sociales más pobres" (DONOSO, 2008, p. 23). No obstante, puede ser insuficiente porque mantiene su carácter neutral ante la complejidad del aprendizaje y los resultados asociados a contextos vulnerables ${ }^{5}$ ni discrimina ante la diversidad institucional y local.

De este modo, uno de los efectos más incesantes y más agudo en el plano regional, fue la reducción de la equidad y el aumento de la segmentación educativa. En consecuencia, acoge a quienes más tienen y menos a quienes urge $^{6}$. Su manifestación es una masiva redistribución de la matrícula y un crecimiento del sector particular a expensas del sector municipal. El proceso se inicia con $80 \%$ de la matrícula del sector fiscal, 15\% del privado subvencionado y $5 \%$ del privado sin subvención. Al día de hoy, el porcentaje de matrícula, en el mismo orden es 48\% 45\% y 7\% (CHILE, 2008a, p. 2).

Las finanzas propiamente municipales siguen otra marcha que, en ocasiones puede alterarse y no ser perceptible ${ }^{7}$. A pesar que los municipios son los responsables administrativos de todas las escuelas y liceos públicos de su territorio, la reglamentación fiscal impide crear impuestos locales y cambiar las tasas de los impuestos ya existentes (COMINETTI; DI GROPELLO, 1998). Es decir, tienen como rasgo esencial su escasa autonomía. El presupuesto proviene de ingresos propios, Fondo Común Municipal y transferencias públicas como privadas ${ }^{8}$.

Por otro lado, las municipalidades pueden aportar económicamente, de manera voluntaria, al sistema escolar de su jurisdicción, con el fin de solventar déficit o realizar inversiones adicionales (CHILE, 2002a). Los aportes son tan diversos como

\footnotetext{
5 Se refiere a un indicador de vulnerabilidad socioeconómica y cultural (Índice de Vulnerabilidad Educativa, IVE) elaborado por una institución gubernamental de asistencialidad para estudiantes más desfavorecidos.

${ }^{6}$ El mecanismo de Financiamiento Compartido incorporado en 1993 selló este aspecto. El cobro a los padres que disponen de capital económico se suma al financiamiento público, generando para sí mismos mejorar la educación de sus hijos. ¿Qué pasa con los padres que no disponen de recursos económicos? ¿Qué pasa con la elección de Escuela? La escuela excluye legalmente a los padres que no pueden pagar y segmenta legalmente por los recursos que se allegan a ella.

7 La innovación del Seguro de Invalidez y Sobrevivencia (SIS) es indicativo. El SIS que había sido financiado por el trabajador, desde julio de 2009 es financiado por la empresa si esta cuenta con más de 100 trabajadores. Sin duda, una medida de protección para el trabajador porque aumenta levemente su ingreso líquido mensual, 1\% aproximadamente. En educación, subvención genera ingresos variables y costos son fijos, el SIS acrecienta los costos fijos. En otras palabras, un municipio con más de 100 funcionarios asume un incremento de las remuneraciones convencional impuesto por ley, sin tener necesariamente soporte económico.

${ }^{8}$ El Sistema Nacional de Información Municipal (SINIM) actualizado anualmente, presenta variables y estadísticas de los 345 municipios del país en áreas de la administración, finanzas, salud, educación, gestión territorial, social y comunitaria, género y caracterización comunal.
} 
municipios existentes y dependen de factores inherentes de la realidad comunal ${ }^{9}$ : captación de ingresos sujetos a condiciones económicas y nivel de ingreso de sus habitantes; capacidad de gestión y de visión política del gobierno local.

\section{El aporte municipal directo a la educación puede ser inexistente o alcanzar el 30\% del} presupuesto total del municipio. En promedio, las municipalidades chilenas contribuyen con el $10 \%$ u $11 \%$ y aumentan en comunas rurales, en términos relativos, no de monto de recursos (CHILE, 2007c). Un mayor aporte municipal no implica mayor compromiso o mejoramiento sustantivo del servicio de educación local. Contrariamente, "lo más frecuente es encontrar que altos aportes se destinan a paliar déficit financiero [...] o, inversamente, que municipios con un bajo aporte efectivamente realizan significativas iniciativas pro-calidad [...], ninguno de los cuales supera el 1\% de aporte municipal" (CHILE, 2007b, p. 23).

Por último, existen políticas de apoyo financiero de carácter provisorio. Es el caso del Fondo de Apoyo al Mejoramiento de la Gestión Municipal en Educación creado en el 2007 que intenta corregir y/o compensar en algunos casos la política de financiamiento. Dicho fondo, sin evaluación de impacto y con traslado parcial o total del presupuesto a la cobertura del Bono Extraordinario Anual de Excedentes (SAE) ${ }^{10}$ el presente año, tuvo entre sus propósitos la identificación de nudos críticos de la gestión, el desarrollo de iniciativas, la creación de capacidades permanentes de todos los actores y el logro de una situación financiera sostenible, como base para avanzar en calidad de la educación. Su texto fija sucintamente una orientación a la politica comunal de educación ${ }^{11}$ que no es centro del mejoramiento, a pesar que en principio el desarrollo "de la educación municipal debe estar sustentado, entre otros aspectos relevantes, en una política que identifique y dé sentido al mejoramiento esperado y en una planificación de las acciones y medios para alcanzarlo" (CHILE, 2007a, p. 7).

\section{Politicas de gestión}

Con el traspaso de escuelas y liceos a la gestión municipal y a la privatización acontecida en los '80, se "estableció uno de los sistemas orgánicamente más descentralizados del mundo, en el que el Ministerio de Educación no cuenta con

\footnotetext{
9 Los aportes al servicio educativo municipal están muy a menudo subordinados a la realidad comunal. Pueden incluso repetir las desigualdades socioeconómicas que se manifiestan en cada territorio. La financiación educacional o subvención y el presupuesto municipal no representan una compensación en este aspecto.

${ }^{10}$ Dicho bono, definido según normativa, produjo las movilizaciones del gremio docente durante el 2009. La mirada pública culpó a la gestión de los municipios, de los alcaldes y de los departamentos de educación. En efecto, la existencia de problemas de gestión y de financiamiento no es debatible, pero acá no es coincidente. Más si los excedentes dependen del número de estudiantes de cada centro escolar, del número de horas de la dotación docente del último mes del año. Es decir, los excedentes pueden existir o no, incluso producir diferencias en contra, entonces, cada municipio tiene la palabra. Particularmente, un cuerpo legal que en su texto generó "diversas interpretaciones" es una ley con errores. Los costos asociados fueron asumidos en su mayoría por las municipalidades de Norte a Sur del país como excedente. Esta situación en sí misma parece inexplicable debido a la sostenida inviabilidad financiera que muestran los municipios históricamente, con lo cual, todavía pueden haber novedades.

${ }^{11}$ Ante el endeudamiento y/o déficit de financiamiento de los municipios la SUBDERE actúa como un Banco de las Municipalidades. El uso del fondo de mejoramiento no promovió una propuesta para diseñar e implementar política educativa municipal, más bien generó una respuesta urgente a la crisis financiera.
} 
facultades para intervenir directamente sobre la gestión de ninguno de los 4.142 sostenedores ni sobre el funcionamiento de sus 10.642 escuelas" (EYZAGUIRRE et al., 2005, p. 43). La llamada descentralización que, en esencia es desconcentración, impone al Ministerio de Educación una profunda desvinculación de todos los centros escolares y de sus respectivos docentes, no los administra. En consecuencia, "de la gestión municipal dependen todos los aspectos administrativos - incluyendo recursos humanos -, presupuestarios y de equipamiento" (COX, 2005, p. 27).

El patrocinio para la municipalización fue la centralización, cuyos rasgos son la ineficiencia, burocracia y rigidez del sector. El Ministerio del Interior aseguraba una gestión más apegada a las características de cada territorio, racionalizando el aparato estatal en unidades más aptas para fiscalizar, utilizar recursos y servicios (PIIE, 1984). Más aún, el municipio mejoraba invirtiendo en educación. En comunas reales, heterogéneas, con autoridades designadas y alineamiento ciudadano, resultó impracticable. "De prestar servicios de aseo, iluminación, pavimentación y distribuir algunos beneficios sociales, debieron pasar a administrar un sistema de gran complejidad" (CHAPARRO, 1997, p. 4), más empeorado porque la transferencia no fue seguida de planificación, capacitación, ni de personal adecuado. No hubo proceso de inducción como tal.

Muchos de los cargos no siempre respondieron a criterios técnico-académicos sino a criterios partidario-políticos con sus constantes conflictos y efectos (HOPENHAYN, 1995). El servicio educativo asumió la cultura del nombramiento, circulación de arbitrariedades, inamovilidad funcionaria y faltas a la legalidad. Por supuesto, sin ninguna clase de costos para los usuarios del sistema. "En los años ochenta todos los directores de establecimientos educacionales municipales [incluidos los jefes DAEM o Corporación] fueron designados ejecutivamente por la autoridad gubernamental" (MIZALA; ROMAGUERA, 2005, p. 522). Modificar estas disposiciones no ha sido tarea fácil. En un primer momento ${ }^{12}$, por la tenaz y sistemática obstrucción de la derecha política en Chile que se expresó en la negativa de aprobar la concursabilidad de todos los directores durante la discusión del proyecto de Estatuto Docente de 1991, cuya "ajustada" solución se resolvió el año $2005^{13}$.

\footnotetext{
${ }^{12}$ Defino en un primer momento porque según y como se han dado las negociaciones en educación, algunos materias han sido claramente rehuidas y otras han concertado alianzas entre el oficialismo y la oposición. Efectivamente han existido "acuerdos" que han sido una suerte de ensamblaje dentro de los principios del neoliberalismo. Entre los ejemplos está la propia Ley General de Educación 20.370/2009, en la cual se mantiene la preeminencia de la Libertad de Enseñanza y del Estado prescindente o subsidiario de la educación.

${ }^{13}$ Ley 20.006/2005 establece concursabilidad de los cargos de directores de establecimientos educacionales municipales. Tal como se expresa es ajustada porque la norma más notable del concurso en cuestión es la permanencia de los cargos. Así, los directores de establecimientos y jefes de educación municipal, pueden decidir postular o no al concurso por cinco años, pueden no ser elegidos y no ser nombrados respectivamente, sin perder su condición de planta en la municipalidad con un sueldo en las mismas condiciones hasta su edad de jubilación.
} 
En relación a la gestión del recurso humano, las condiciones laborales experimentaron un deterioro sensible. Los docentes traspasados al código laboral del sector privado y a criterios de cada municipio, dejaron ver una serie de irregularidades: disparidad de sueldos, pérdida de carrera funcionaria existente, anulación de leyes laborales precedentes y fragmentación del gremio docente. La gestión del recurso material se asimiló a las instrucciones emanadas del Ministerio de Educación Pública ${ }^{14}$.

\section{Si bien la administración municipal sigue poderosamente ligada a la estructura institucional del Estado porque desde alli se delimitan sus ingresos, funciones y atribuciones. No son menos importantes, las capacidades técnico-políticas de las autoridades y de los funcionarios municipales que están detrás de la prestación del servicio educativo y que deben asegurar una eficiente gestión municipal. No obstante, el tema clave de recursos humanos en Chile, salvo ligeras modificaciones, sigue ausente de un debate profundo para fortalecer los gobiernos locales.}

La cultura organizativa de la gran mayoría de los municipios sigue embebida en el duradero legado centralista del caudiIlismo, cuya vigencia se nutre de la falta de estabilidad laboral en los cargos gerenciales y de la rotación de una burocracia mal pagada y excesiva (NICKSON, 2005, p. 184).

\section{El mejoramiento de la gestión no es materia destacada. La afirmación puede} ajustarse al Municipio ${ }^{15}$ y al Ministerio de Educación. Este último, "ente complejo" (PNUD, 2004, p. 136) con múltiples competencias y autonomía, baja coordinación interna y notable burocracia, en resumen, no ha generado sistema. Lo cual implica fiscalizar, delegar responsabilidad y autoridad en los niveles subnacionales con sus concernientes recursos. No es facilitador del desarrollo educacional regional y local ${ }^{16}$. En otro extremo, los gremios docentes y funcionarios, más especificamente su dirigencia, tampoco se han mostrado proclives a estos cambios, más bien, resistentes ${ }^{17}$. El deterioro de la educación pública es más profundo, "la captura de la que fue objeto antes y también ahora por parte del

\footnotetext{
${ }^{14}$ Por ejemplo, el nivel central adquiría los textos escolares para todos los establecimientos educacionales del país y seguidamente, enviados a los departamentos provinciales. A continuación, se informaba a los municipios para su recogida y posterior distribución en las escuelas y liceos de su localidad. El proceso habitualmente incurría en atrasos.

${ }^{15}$ Según Armijo (2002) la década de los '90 impulsa una reforma al Estado con indicaciones expresas: factible, gradual, parcial, donde los incentivos, demandas y orientaciones sobre los gestores institucionales eran esenciales. La modernización está dirigida a la administración central del Estado (ministerios y servicios públicos), dejando fuera a los gobiernos locales y las empresas públicas.

${ }^{16}$ Es difícil comprender que el Ministerio de Educación siga sus prácticas anquilosadas sólo por tradición o asiduidad. Sin reservas, en muchos aspectos ha mantenido un itinerario errático, parece no saber qué hacer en su nivel central, no es ni decidido, ni gradual y mucho menos sistemático, parece no saber qué hacer con las SECREDUC y DEPROV, descongestiona con ambigüedad de tareas y con espacios simbólicos de autonomía en sus niveles subnacionales.

${ }^{17}$ En una suerte de paradoja, la dirigencia del gremio docente negocia sus demandas (la mayoría de carácter remuneracional) centralizadamente con el Ejecutivo, representado por el Ministerio de Educación y con la Asociación Chilena de Municipalidades (AChM). Mejor dicho, el Ministerio actúa como administrador ante el gremio docente, aunque éste fue atomizado con la municipalización educativa y cada municipio es "el administrador".
} 
gremio docente, y este proyecto [se refiere al proyecto de ley que fortalece la educación pública] no hace nada por remediar esta situación u otras que pudieran estar a la base del fenómeno observado" (BEYER, 2009, p. 101).

\section{Durante los noventa, las innovaciones en este ámbito acontecían al menos} teóricamente, en las escuelas o liceos. Por ejemplo, se comenzó a hablar de proyecto educativo asentado en la planificación estratégica, el liderazgo técnico del director y el trabajo del equipo docente. Mientras que departamentos o corporaciones municipales quedaron excluidos. De manera que, disposiciones, reformas y demandas siguieron pasando raudas del nivel macro al micro (institucional) obviando el nivel intermedio de la cadena. No hubo incorporación de las esferas locales de educación o nexos de colaboración sistemáticos. Los esfuerzos han sido a voces insuficientes, incluso erróneos en muchos casos.

En materia de gestión, a contar de 1996 los municipios deben planificar anualmente sus metas educativas, prioridades y distribución de recursos en atención a diagnósticos, políticas y proyecciones locales y la participación de la comunidad escolar $^{18}$. El Plan Anual de Desarrollo Educativo Municipal (PADEM) surge en la Subsecretaria de Desarrollo Regional sin objetivos comunes y compartidos con el Ministerio de Educación ${ }^{19}$. El desencuentro es manifiesto-de manera muy general, se valora positivamente-. Sin embargo, los instrumentos de planificación asociados a la gestión municipal, al desarrollo territorial, llámese Plan Comunal de Desarrollo (PLADECO) y PADEM se precipitan y en la práctica, se convierten en meros documentos oficiales. Al parecer, la política de descentralización avanza sin las regulaciones correspondientes y/o falta coherencia en su normativa. De hecho, los componentes financieros y administrativos no han sido asegurados, es más, no existen mecanismos que regulen y evalúen dichos instrumentos.

\section{La Ley ${ }^{\circ}$ que ordena el PADEM no tiene respaldo intersectorial (que significa),} ningún organismo puede garantizar el cumplimiento de la política de descentralización educativa expresada por ley (CHILE, 2002b). Finalmente, si

\footnotetext{
${ }^{18}$ El PADEM es un instrumento de planificación "anual" validado por un cuerpo legal que no contempla recursos precisos para diseñar e implementar política educativa local, ni asume la heterogeneidad de los territorios o el carácter comprensivo definido en la $\operatorname{OCDE}$ (2004, p.73). El plan debe contemplar un diagnóstico de las escuelas y liceos; un análisis de la oferta y demanda de la matrícula escolar; las metas municipales y de los centros educacionales; los programas de acción pertinentes; la estructura del presupuesto (ingresos, gastos e inversión); la dotación docente y no docente. Para la mayoría se ha incorporado como parte del cumplimiento de la burocracia municipal, donde es deber esencial del Alcalde presentar al Concejo o corre el riesgo de ser acusado de abandono notable de sus funciones, pero no existe presión para monitorear procesos ni evaluar resultados de la planificación desarrollada, salvo contadas excepciones.

${ }^{19}$ Para el MINEDUC, el plan se creaba únicamente para solucionar los problemas económicos de la educación municipal. Un arma de racionalización financiera que, luego, sin ser negativo, amplió sus expectativas a otros ámbitos de planificación. En contraste, para la SUBDERE se disponía como instrumento de planificación, reconociendo al municipio como actor responsable de la educación frente a la comunidad.

${ }^{20}$ Ley 19.410/1995 modifica la ley 19.070 , sobre estatuto de profesionales de la educación, el decreto con fuerza de ley № 5/1993, del Ministerio de Educación, sobre a subvenciones establecimientos educacionales y otorga beneficios que señala.
} 
bien se "busca tanto mejorar el gobierno y la gestión local (que en muchos casos ni siquiera estaba realizando este tipo de análisis básico) como la transparencia, accountability y la participación de la comunidad" (GONZÁLEZ, 2005b, p. 640), es más habitual que los Departamentos o Corporaciones se contagien con la dinámica del trabajo municipal y se muestren más preocupados por las tareas asignadas ${ }^{21}$ y crecientes ${ }^{22}$, que por crear o buscar fórmulas que permitan innovar en el campo de la calidad de la educación. Para esto coexisten varios motivos: la propia conducción de las acciones, gestión altamente personalizada en la figura del Alcalde, papeleo en abundancia, falta de recursos para materializarlas, incapacidad para movilizar voluntades, tendencia a seguir las instrucciones ministeriales o tiempo que supone un proyecto al interior del municipio, entre otras.

\section{Politicas de participación y conviavilidad}

El gobierno de la comuna del régimen militar se configuró a través de una administración local tecnificada y un sistema de participación ciudadana sin democracia (ESPINOZA; MARCEL, 1994). La participación se situó en la nueva institucionalidad comunal y en el reforzamiento del poder local. Los organismos afines no representativos, elegidos por la autoridad, con labores consultivas y asesoras, eran el Consejo de Desarrollo Comunal (CODECO) en el municipio y los centros de padres y apoderados (CPA) en los establecimientos educacionales. Naturalmente, uno y otro observados en su funcionamiento e impregnados de autoritarismo. La participación subsistió en la retórica pero no hubo siquiera esbozos para canalizarla, por lo tanto, es lícito creer que no existió "a nivel de gobierno una intención real de conceder espacios de participación en el proceso educativo a ninguno de los actores involucrados en éste y menos a la comunidad" (EGAÑA; MAGENDZO, 1985, p. 98).

La década del noventa buscó restablecer la convivialidad ${ }^{23}$ ciudadana. Ejemplo de ello son las elecciones municipales, las cuales redundarían en participación más activa e integración más significativa en las actividades de gestión municipal. Aún así, hubo más obstáculos y las pocas iniciativas no se generalizaron, "ya que no se modificaron

\footnotetext{
${ }^{21}$ Una política educativa diseñada en el Ministerio de Educación implica, en la mayoría de los casos, disponer de recursos humanos y materiales en el proceso de implementación. A menudo, los procedimientos pasan por alto sus condiciones de base, el plan de educación que puede estar desarrollando un municipio en cuestión, algunos dispositivos de ajuste y la financiación total de las nuevas responsabilidades que se trasladan.

${ }^{22}$ Desde el 2003 aproximadamente, a los jefes de educación municipal se les hace responsables de la implementación del proceso de evaluación docente. De esta manera, los directores incorporan una función más, la administración operativa de la evaluación docente municipal que, en forma muy breve encierra: capacitación específica para hacer el trabajo, ejecución del proceso en su conjunto y mantención de un sistema de información permanente.

${ }^{23}$ Se refiere a la vida en común, colectiva, pública, de asociación ciudadana, por años paralizada. La reorganización de la participación en un contexto de individualización requiere mayores esfuerzos, confianzas y condicionantes individuales que la determinan. Un modelo de desarrollo como el nuestro, debilita lo colectivo, atomiza a la sociedad y la hace competir ante sus necesidades a través del subsidio a, subsidio b, subsidio c.
} 
los procesos administrativos y de toma de decisiones" (NICKSON, 2005, p.196). Atenta contra la propia visión de participación de algunos gobiernos locales bastante limitada. Es decir, no existe un interés genuino de incorporación a los apoderados en el diseño de estrategias educativas hacia la comunidad o se conforma con el acercamiento tradicional: los aportes para infraestructura y equipamiento que los apoderados suelen hacer a la escuela o liceo (LATORRE et al., 1991).

Aunque no ha sido del todo auspicioso se han restituido o abierto canales de participación tales como el Concejo Municipal, los Centros de Padres y Apoderados, los Centros de Alumnos y los Consejos Escolares ${ }^{24}$. Estos últimos de carácter consultivo, informativo y propositivo estipulan un diálogo entre los actores educacionales, pero "la cultura escolar predominante hace que en un futuro cercano, no esté para nada garantizada su efectiva operación" (MONTT et al., 2006, p. 9). A la problemática anterior se agrega que éstos no han sido percibidos por los interesados como medios de interlocución válida, no parecen explícitos ni consistentes ${ }^{25}$. Lentamente, se van institucionalizando pero no interiorizando en la comunidad, y por derivación, son absorbidos por las actividades rutinarias del municipio y de la escuela. "Claramente, una mayor participación de los padres en el sistema educativo implica un cambio en los actuales equilibrios de poder, lo cual provoca resistencias entre los otros actores" (BELLEI; GUBBINS; LÓPEZ, 2002 apud PNUD, 2004).

Igualmente, en la metodología de planificación educativa local e institucional se incorporan mecanismos de participación de los distintos estamentos. No obstante, tanto el PADEM como el Plan Educativo Institucional (PEI) son a menudo subutilizados, producto de las decisiones estratégicas de los responsables de su elaboración, del desconocimiento de la comunidad o del bajo interés de la colectividad para participar en los procesos educativos. Tales incidencias, diluyen eventuales aportaciones, compromisos e involucración de la comunidad en el tema educativo. Otra particularidad es que rara vez se convoca a otros agentes de la comuna que no sean apoderados, docentes o alumnos.

Los mecanismos existentes, debido a la forma en que se utilizan, siguen manteniendo a los ciudadanos al margen de las decisiones del proceso y gestión escolar. Los organismos educativos como DAEMs, corporaciones, equipos

\footnotetext{
${ }^{24}$ La Ley 19.979/2004 en sus artículos 7, 8 y 9 obliga a la constitución de los Consejos Escolares en todos los establecimientos subvencionados del país. Aunque han sido definidos como ejemplo de innovación institucional cuya estructura de base es la coordinación y participación entre actores del centro y la comunidad pueden limitarse a la formalidad y en cierto modo, al conflicto. Por lo demás, son resolutivos sólo si el sostenedor decide darle este carácter.

${ }^{25}$ La política de convivencia escolar del año 2003 es otro ejemplo que enfatiza los derechos, la democratización y la cultura cívica en el entorno escolar. Se trata de un nuevo modelo de interacción entre los actores de la comunidad educativa que influye directamente en el desarrollo ético, social, afectivo e intelectual de los/as alumnos/as. Pasados los años, la política no se ha implementado en todos los centros escolares ni en sus aulas porque precisa de cambios progresivos, paso a paso, que reorienten la cultura escolar en cada caso particular.
} 
de gestión de los establecimientos educativos se apropian, casi de manera exclusiva, de las decisiones y de la planificación de las actividades educativas. Ello trae como resultado que, aunque la participación ciudadana sea un supuesto que garantice mejores resultados, no tenga una respuesta elocuente en la medida en que los ciudadanos están poco representados al no haber sido integrados al proceso de su construcción (CHILE, 2002a, p. 41).

Por lo mismo, la participación ciudadana en términos de control social es casi nula, sin obviar, la heterogeneidad de gestión de los municipios. Si bien se ha agendado rendición de cuentas públicas en el municipio y en los centros educativos, su carácter es estrictamente nominal y mínimo en objeciones. Por otro lado, el concepto participación tiene una acepción bastante arraigada en la comunidad asociada al hecho de ingresar, asistir o usar el servicio educativo. También ligada a procesos operativos (gestionar o ejecutar diseños de terceros) y contributivos (aportar dinero, especies, tiempo, trabajo). Pero lo cierto es que la comunidad no es indiferente a la educación, representa un mecanismo esencial de movilidad y progreso social.

La educación en esta sociedad tendrá que ser entendida cada vez más como un tema que requiere la colaboración de muchos actores e instancias sociales; como un tema que no puede quedar circunscrito a las estrecheces de una concepción sólo vinculada a la transmisión de conocimientos; como un tema que requiere más diversidad en la provisión de servicios y en la capacidad de aprovechar los recursos y la fuerza de las comunidades locales (SUBIRATS, 2005, p. 186-187).

Para finalizar, los agentes responsables concuerdan que la participación de la comunidad plasmada en colaboración, fiscalización y control del servicio aportaría mayor eficiencia. La familia, de hecho, empieza a demandar educación agregando de calidad. A pesar de la Escuela y del municipio que insisten en "endosar" a los apoderados descuido o indiferencia porque no se involucran ni desarrollan acciones de colaboración y control de la calidad del servicio entregado. La realidad revela mayor pereza en estas entidades, subutilización de los medios disponibles ${ }^{26}$ y "total ausencia de estrategias para fomentar una relación intencionada con los padres" (MONTT et al., 2006, p. 56). Esta tendencia señala que en cada territorio aumenta el interés por la educación. Los municipios que incorporan seria y gradualmente en su política educativa distintos actores para el proceso, no sin dificultades, consiguen mejores resultados.

\footnotetext{
${ }^{26}$ La existencia de dispositivos para participar en la comunidad local y en los centros educativos no implica que la acción se lleve a cabo en plenitud. Es decir, la política por sí sola, más aún si trata de participación, no va a alcanzar a los objetivos, a menos que haya voluntades partiendo de sus autoridades para legitimar estas experiencias, para validarlas como parte de la vida democrática de la Escuela.
} 


\section{Politicas de regulación}

Las políticas de regulación son las normas o reglas que permiten ordenar el sector y asegurar que la educación de calidad llegue a toda la población escolar del territorio. Los reglamentos para el sector municipal se iniciaron en paralelo con el traspaso del servicio de educación a la esfera local y con la división de tareas administrativas y pedagógicas ${ }^{27}$. Así, las principales actividades administrativas del Ministerio de Educación Pública fueron transferidas a los sostenedores municipales que, son regulados por los códigos que rigen a las municipalidades ${ }^{28}$.

Los sostenedores municipales o privados asumían la representación legal y por ende, velarían por el correcto funcionamiento de los centros educativos y por la adecuada gestión de los recursos humanos. Al Ministerio correspondía la supervisión técnico-pedagógica a los establecimientos cooperadores de la función educacional del Estado tanto municipal como particular y, la inspección y control de las subvenciones asignadas a dichos sostenedores, cautelando el cumplimiento de la legislación y reglamento de subvenciones. El Ministerio delega tales acciones en sus órganos desconcentrados: Secretarías Regionales Ministeriales y Departamentos Provinciales de Educación.

El cambio gubernamental de los noventa no varió los procedimientos. Los inspectores visitan 2 a 4 veces al año los centros educativos de manera imprevista, observan el estado del edificio y el cumplimiento administrativo, especialmente, los registros de asistencia de los alumnos por su relación con la subvención educacional. Los supervisores visitan concertadamente con los directores, en ellas, ofrecen asistencia técnica y "bajan información" respecto de programas y nuevas políticas (MONTT et al., 2006). Ambos son funcionarios "en terreno" y representan la cara visible del Ministerio de Educación. Por lo demás, ninguno de los órganos desconcentrados se articula con el servicio municipal de educación. La política educativa se plantea entre supervisores e inspectores y las instituciones educativas marginando la zona intermedia de gestión, los departamentos o corporaciones de educación municipal.

La tradición centralista del sistema ha omitido la actuación local y las políticas de corrección al respecto han sido tardías, poco eficientes e incluso contradictorias. Aunque las autoridades de uno u otro nivel coinciden en las dificultades de la educación municipal y en el transcurso se han modificado los

\footnotetext{
${ }^{27}$ En ningún caso significó una nueva institucionalidad educativa. La rebelión de los pingüinos reveló una despojada institucionalidad educativa, sin definición de responsabilidades y con restricciones profundas para hacer sistema.

${ }^{28}$ El Código del Trabajo rige a los funcionarios municipales, éstos a su vez, tienen sus propios estatutos municipales.
} 
escenarios, a la fecha, subsisten los esfuerzos por establecer alianzas entre el ministerio y las municipalidades con sus distintos grados de apropiación y avance, con el propósito de trabajar de forma sinérgica el mejoramiento de la educación de cada territorio (SERRANO; FERNÁNDEZ; PÁVEZ, 2001).

Esta relación asimétrica también se percibe con los empresarios privados producto de las tibias regulaciones y la propia autonomía que éstos contemplan. El ministerio parece más ausente del acontecer de los colegios privados subvencionados con fondos públicos, salvo algunas excepciones. Concretamente, la institucionalidad educativa se ciñe más sobre los sostenedores públicos, sin resolver el conflicto de la descentralización llevada del modo: principal/agente ${ }^{29}$. Las transferencias financian funciones que el nivel central (principal) quiere que los niveles municipales y establecimientos educacionales (agentes, diversos en este caso) cumplan, pero no puede asegurar que se cumplan ciertos objetivos y metas educacionales, ni verificar la eficiencia y eficacia de esas acciones; ni garantizar que se cumplan aquellos objetivos de bien público asociados a la educación ${ }^{30}$.

El sistema de supervisión, abiertamente criticado, exterioriza más una cadena de falencias que una función adecuada como reducido en personal, bajo en competencias, no retroalimenta las decisiones de política. "En el mundo real de la educación chilena, los profesores están en su mayor parte solos en sus clases, sin supervisión ya sea de los padres o supervisores con conocimientos" (OCDE; CHILE, 2004, p. 292).

En la actualidad, los municipios demandan al ministerio participación horizontal y renovada en la educación de su territorio y, el ministerio, comprende lentamente, la relevancia del municipio para la sustentabilidad de cualquier política promovida desde su nivel. Un ejemplo son los equipos técnicos pedagógicos conformados en los municipios, no sólo para recibir y ejecutar instrucciones, sino para apoyar a los escuelas y liceos de su jurisdicción, incluso adelantándose a los modelos de asistencia técnica del Departamento Provincial de Educación. No es generalizado, sólo 120 municipios poseen un equipo profesional estable de apoyo y, dentro de éstos, 32 cuentan con equipos técnicos de mayor desarrollo y complejidad (PÁVEZ 2004; CORNEIO, 2006). Se trata de municipios "de mayor tamaño y con mayores capacidades institucionales y financieras en una dimensión que formalmente es atribución exclusiva del Ministerio de Educación: las materias técnico-pedagógicas" (CHILE, 2005, p. 16).

\footnotetext{
${ }^{29}$ Los niveles subnacionales poseen un grado de independencia relativa en casi todas las principales funciones, pero responden en medida importante al nivel central por sus acciones, debido a la estructura de financiamiento muy dependiente de ese nivel y a la vinculación a normas e incentivos de cierta intensidad que él establece.

${ }^{30}$ De hecho, el mismo Ministerio de Educación no ha logrado, después de casi tres décadas, una política armónica que contemple lo nacional - regional - provincial - local, tiende más a la superposición de los niveles u a la omisión en último caso.
} 
Desde otra mirada, la Contraloría General de la República se encarga de la inspección financiera del municipio para asegurar la legalidad de los gastos y la generación de los ingresos municipales. Es un proceso reglamentado a través "de auditorías a priori y a posteriori de las cuentas municipales, en las que se controla tanto la preparación y la ejecución de los presupuestos, como la compra y venta de activos municipales" (NICKSON, 2005, p. 191). No incorpora técnicas gerenciales ni realiza análisis comparativos, por lo tanto, ofrece escasa información en cuanto a la eficiencia de la administración y eficacia de la prestación de servicios locales. Cabe agregar, que si bien el ministerio transfiere recursos a los municipios (que en algunos programas no alcanza al 100\%) y espera de éstos una adecuada gestión utilizando criterios de eficiencia económica, no cuenta con capacidades ni mecanismos formales de regulación que verifiquen esta gestión ${ }^{31}$. Además, la propia subvención mantiene la división de los aspectos educativos y financieros. (SERRANO; FERNÁNDEZ; PÁVEZ, 2001).

Con respecto a ciertos procedimientos ligados a las regulaciones, en su mayoría, no son de interés público y no implican mayor participación, son un espacio dentro de la "normativa" para entregar información del estado de los recursos, sin interlocución con la colectividad local y escolar (CHILE, 2002a). La rendición de cuentas se incorpora en la rutina municipal y escolar, pero no actúa como círculo de información que permita evaluar y regular para el mejoramiento de los procesos educacionales. El monitoreo y la evaluación definida en la política educativa, en programas especificos o en los proyectos educativos institucionales, es una actividad rudimentaria en la estructura central, local y escolar. A excepción del SIMCE, algunos municipios aprovechan este sistema de medición para evaluar los resultados locales y redireccionar sus estrategias de aprendizaje.

El movimiento de estudiantes secundarios dejó ver el menoscabo institucionalidad y generó un consejo asesor que sin llegar a acuerdos substanciales, intencionó una evolución expresada en proyectos de cuerpos legales con inclinación a las regulaciones en todos los niveles y actores del sistema educativo. La primera y recién promulgada Ley $n^{\circ} 20.370$ (CHILE, 2009). La segunda en trámite, es un proyecto de ley que fortalece la educación pública y en la cual se explicitan principios de la educación pública y de los sostenedores públicos, la creación de las Corporaciones Locales de Educación Pública y del Servicio Nacional de Educación. Y la tercera también en trámite, sobre el sistema nacional de aseguramiento de la calidad de la educación parvularia, básica y media. Esta última, esencialmente, instituye la Agencia de Calidad de la Educación que debería evaluar y orientar la mejora de la calidad y, por otro lado, crea la Superintendencia de Educación para fiscalizar los establecimientos educativos y sus sostenedores.

\footnotetext{
${ }^{31}$ Los estudios realizados a los Municipios, Departamentos de Educación Municipal o Corporaciones han mostrado cierta caracterización del déficit financiero y del endeudamiento. De hecho, datos recientes explicitan que dos tercios de los municipios estudiados acusan morosidad en la cancelación de imposiciones previsionales, remuneraciones, asignación de perfeccionamiento y otros específicos que afectan al personal docente municipal.
} 
Al día de hoy, el Ministerio de Educación en su "nueva arquitectura de la educación chilena" mantiene el diseño de la política, del marco curricular y de los planes y programas, la elaboración de las leyes y de los estándares, el registro de la información y el financiamiento del sistema. Indudablemente existen cambios, pero las expectativas no pueden ser demasiado ambiciosas en esta materia, por cuanto están en conflicto dos principios básicos. El derecho ciudadano a la educación y la libertad de enseñanza no se resuelve y sigue abierto el debate.

\section{Politicas del Currículum}

Desde el inicio, la municipalización contempló la escisión del sistema educativo, a saber en aspectos administrativos y técnico-pedagógicos. Aunque es imposible e improcedente "establecer con claridad los límites de lo administrativo y de lo técnico pedagógico" (LATORRE et al., 1991, p. 41) en el terreno educacional. Es en esta fractura que los municipios quedaron totalmente excluidos para decidir sobre los contenidos pedagógicos que se impartían en las escuelas y liceos de su territorio. Si bien los planes y programas de estudios de enseñanza básica y media elaborados entre 1980 y 1983 señalaban como principios la flexibilidad, la descentralización y la adaptación curricular "a las necesidades y realidades en que los programas son desarrollados" (EGAÑA; MAGENDZO, 1985, p. 35). En el contexto de privaciones y autoritarismo, las medidas provocaron efectos negativos, especialmente, sobre la educación de los más pobres (COX, 2005). Por ejemplo, dichos principios promovieron un currículum reducido y pobre en exigencias; autorizando a los establecimientos educacionales para determinar el tiempo dedicado al aprendizaje, para elegir entre algunas materias e incluso, para eliminar asignaturas.

Al mismo tenor, descartada la flexibilidad curricular para realizar adaptaciones en el medio local o la posibilidad de ir generando currículum en los niveles regionales y comunales. En algunas municipalidades surgieron iniciativas esporádicas como enfatizar asignaturas o crear un área de estudio especifica, pero ninguna logró consolidarse. Para los municipios cualquier innovación del currículum implicaba soporte financiero y como para éstos el presupuesto usualmente era insuficiente, las decisiones al respecto se trasladaron al plano marginal. Por lo demás, los ámbitos de acción de las autoridades locales estaban circunscritos a las tareas administrativas del sistema, controlaban una parte del proceso, ciertamente, bajo las directrices y normativas derivadas del Ministerio de Educación.

En el ocaso del régimen militar, la promulgación de una ley de educación, conocida como LOCE aseguró la política educativa precedente ${ }^{32}$. En materia de gestión

\footnotetext{
${ }^{32}$ La Ley № 18.962 Orgánica Constitucional de Enseñanza del 10 de marzo de 1990 reafirmó la continuidad de los dispositivos de mercado puestos en práctica, básicamente: selectividad de alumnos, municipalización educativa, financiamiento vía subvención a la demanda no diferenciada entre empresarios públicos y privados.
} 
curricular, el Ministerio de Educación centralizaba la propuesta, previa aprobación del Consejo Superior de Educación -organismo autónomo con personalidad jurídica y patrimonio propio-, sería responsable de la definición curricular de la enseñanza básica y media. No obstante, los centros educativos tenían autonomía para fijar sus propios planes y programas de estudio, pero fue débil su sistematización. Sin entrar en detalles, fue un dispositivo legal más, "difícilmente modificable, una acción limitada y controlada del Estado en educación" (GYSLING, 2005, p. 216).

Dentro de los márgenes impuestos por la nueva legislación, el Ministerio de Educación reposicionó su protagonismo en componentes curriculares. Validó la flexibilización, sobre la base de responsabilidades compartidas entre el Estado y los establecimientos educacionales. En otros términos, prescribió un currículum

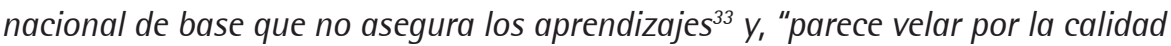
de los procesos pedagógicos" (CORNEJO, 2006, p. 121). Para su cometido, cuenta con una multiplicad de programas oficiales y se relaciona directamente con los centros educativos desde sus organismos desconcentrados. Simultáneamente, posibilitó que los colegios, no el contexto local, ampliaran este currículum de acuerdo a sus propios requerimientos de enseñanza.

A pesar que los establecimientos educacionales quedaron facultados para elaborar sus propios planes y programas de estudio de acuerdo a sus consideraciones y prioridades de organización, sólo alrededor de un 14\% adoptó esta modalidad. En otras palabras, el diseño y la elaboración curricular no están generalizados.

Este porcentaje se explica si se considera que: no existía en el pais precedente de elaboración curricular a nivel local; los profesores no han sido formados para elaborar currículum ni tienen las condiciones laborales que les permita hacerlo; los establecimientos, por su parte, tampoco tienen la instancia organizacional que pueda hacerse cargo de esta tarea; y, por último, el Ministerio no ha emprendido acciones específicas para fomentar la elaboración curricular propia (GYSLING, 2005, p. 239).

Los planteamientos en cuestión formaron parte de la Reforma Educacional de mediados de los noventa que tenía como elemento central: la transformación curricular en todos los niveles de enseñanza cimentada en el enfoque constructivista del aprendizaje. A la par, se incorporaron otros lineamientos como la focalización de programas de mejoramiento educativo; la profesionalización docente y la ampliación de la jornada escolar. La política educacional del período,

\footnotetext{
${ }^{33}$ La definición del currículum no asegura los aprendizajes de los alumnos, prueba de ello, son los resultados de Sistema Nacional de Evaluación de resultados de aprendizaje como también los Niveles de Logro que describen en forma cualitativa los aprendizajes que los estudiantes son capaces de demostrar en la prueba del SIMCE.
} 
casi en forma exclusiva, se orientó a los establecimientos educacionales, excluyendo los niveles intermedios del sistema, más a los sostenedores municipales. No se consideraron las aportaciones y/o compromisos que los municipios pueden realizar desde su perspectiva administrativa que, indudablemente, son relevantes en el funcionamiento pedagógico.

En la visión de Donoso (2005, p. 121), tener la escuela como centro de la acción fue una estrategia ministerial para disminuir los efectos de la parcelación ministerio y municipios. Tal situación, impide al primero "un adecuado control del hacer escolar más allá de algunas dimensiones importantes, pero de carácter formal y claramente insuficientes para responsabilizarse del proceso pedagógico, como se le demanda al Ministerio, sin tener un soporte legal consistente con esta misión"

Obviamente, el problema no fue el protagonismo de uno u otro nivel en la formulación del cambio curricular. Con el retorno a la democracia, el Ministerio de Educación era sin lugar a dudas, la institución más indicada para hacerse cargo de una transformación profunda y compleja como es el aprendizaje de todos los estudiantes de enseñanza básica y media del país. No obstante, actores directamente involucrados como los Departamentos de Educación Municipal o Corporaciones, en sus labores administrativas, no fueron convocados a participar en este terreno de decisiones, con lo cual, involucración y compromisos de las autoridades locales, también resultaron afectados. Una vez más, se actuó con omisión.

Un ejemplo que puede ser representativo son las actuaciones de unos y otros ante los instrumentos de microplaneamiento institucional, los Proyectos de Mejoramiento Educativo (PME) que se desarrollaron en las escuelas y liceos del país. En los hechos, los proyectos no estipularon respaldo técnico del municipio, sólo una relación formal de transferencia de recursos entre los departamentos provinciales y las escuelas. No se establecieron capacidades técnicas en los niveles provinciales y locales para evaluar el impacto de los proyectos ni recursos para dar continuidad a aquellos con mejores resultados, más allá del plazo de tres o cuatro años que disponían de financiamiento ministerial (ALVAREZ, 1995).

Pese a los avances señalados, queda pendiente enlazar la descentralización administrativa generada en los años 80 con este esfuerzo de descentralización pedagógica impulsado por las políticas de los años 90. Esta desarticulación no es inocua, ya que genera fuertes tensiones en el sistema y afecta de manera muy práctica la implementación de las políticas (GARCÍA-HUIDOBRO; SOTOMAYOR, 2005, p. 310). 
En resumen, la elaboración curricular puede describirse como un proceso prolongado y serio, de difícil convocatoria. Las articulaciones y acompañamientos, cada día más ineludibles, que un nivel subnacional como la municipalidad hubiese podido aportar a través de un trabajo sinérgico basado en la co-responsabilidad, más allá de las normas, quedó de plano anulado. Si bien dentro del marco curricular oficial existe una orientación a la descentralización, esto no implica que en su diseño establezca complementación y/o adecuación curricular dirigida al territorio, a lo local. Todo sigue al día de hoy, sin corregirse.

\section{Conclusiones}

El proceso de desconcentración implantado en el país en los años los ochenta y en forma especial la municipalización no tuvo por finalidad el diseño e implantación de políticas educativas locales, ni tampoco transformó en forma sustantiva el entorno centralista de la educación. No constituyó definición, adaptación o innovación de políticas nacionales en contextos locales, tampoco generó planes educativos asociados a los entes subnacionales. En este orden de cosas, el discurso superó toda realidad. Si bien el municipio representaba el organismo más cercano a la ciudadanía, en esa misma proporción permanecía intervenido y su papel no era más que ejecutar las políticas ya diseñadas desde las instituciones centrales del gobierno, incluidas las de educación.

A inicios del gobierno democrático en los noventa, la municipalización fue masivamente criticada por su baja legitimidad, el deterioro de la profesión docente, los problemas financieros, la caída del valor de la subvención; la ineficiencia de las administraciones municipales y el fraccionamiento institucional en aspectos administrativos municipales y técnico-pedagógicos ministeriales. A pesar de la presión ejercida para devolver a los centros educativos al ministerio, las autoridades insistieron en la validez de la descentralización, no sin modificar algunas de sus fallas. Pero en esencia, las bases de la estructura no cambiaron.

Después de casi dos décadas de estrategias para mejorar la calidad de la educación, la percepción negativa de la municipalización subsiste, como también sus históricos problemas. En todo caso, en tal proceso únicamente se había convocado a la llamada "unidad básica de administración", a decir: la Escuela, sin contemplar el nivel intermedio responsable de la gestión. En la dinámica de funcionamiento (hasta hoy pese a los incruentos esfuerzos) el Ministerio y el municipio mantienen carriles separados, donde el primero define todas las acciones del segundo, pero, legalmente, no cuenta con atribuciones para intervenir en la actuación del sostenedor municipal, este último es regulado a través de las leyes que rigen a las municipalidades. 
Ciertamente, la política educativa local tiene como finalidad avanzar hacia un sistema educacional más equitativo, más contextualizado y por ende, de calidad para todos los/as alumnos/as pertenecientes a un territorio particular. Aunque revele singularidad, sigue siendo compatible con la politica nacional. Un sistema con estas características requiere, además de políticas definidas y programas pertinentes, replantearse el papel del Estado, modificar la institucionalidad vigente y redefinir prácticas cotidianas de los distintos actores sociales.

No obstante, a toda vista, la política educativa en el contexto local debe tener en cuenta algunas consideraciones para intencionar su despegue desde los gobiernos locales. Son, por un lado, contenidos pendientes que enfrenta la educación municipal desde su implementación hasta estos tiempos, sí está de verdad sensibilizada y comprometida ante los requerimientos educativos de los niños y jóvenes de su territorio y, por otro, son evidencias potenciales que pueden abrir expectativas de mejoramiento. Algunas de estas son que:

- A nivel macro, la política de descentralización efectiva no tiene avances significativos en normativas y articulaciones necesarias para el ejercicio de los niveles subnacionales de educación. El modelo de transferencias intersectoriales es jerárquico. Liderado por el MINEDUC y en ocasiones por la SUBDERE, "baja" hacia toda la comunidad educativa nacional, pero no genera un proceso inverso desde la especificidad local que informe y retroalimente.

- El diseño de política no formaliza labores conjuntas, participativas y responsables en planificación y en ejecución de actividades educativas en los distintos niveles de decisión involucrados. El ministerio no ha variado en principio su misión y procedimientos centralizados, no intenciona mecanismos de responsabilidad compartida con la gestión de la educación municipal ni aprovecha las oportunidades que cada territorio puede ofrecer.

- Las leyes que rigen a los municipios deben disponer medidas a fin de prevenir actuaciones políticas que menoscaben la función social de la educación y disminuir manejos arbitrarios o intereses no colectivos. Igualmente, los planes de desarrollo comunal y los recursos disponibles, consolidar estrategias de información con instancias reales para que tanto la comunidad como la opinión pública local participen y ejerzan control social en las tareas encomendadas a las municipalidades.

- En la actualidad, existe cierto consenso en consolidar el papel educativo del municipio como responsable de la globalidad del proceso. No obstante, el desempeño del servicio educacional no es independiente del tamaño y 
riqueza de la localidad. La multiplicidad de escenarios locales es patente. Las políticas educativas no reconocen la heterogeneidad que el territorio presenta por ubicación geográfica, patrimonio local o los atributos del representante legal para manejar los recursos.

- En este mismo sentido, la política educativa a lo largo de los años, elude conocer el precio (valor) de una educación de calidad en cada nivel socio económico y cultural existente en el país. También ignora el amplio rango de características de los estudiantes que concentra la escuela o liceo municipal: provenientes de los sectores más vulnerables de la población, en riesgo social y/o con antecedentes escolares complejos.

Finalmente, las futuras agendas gubernamentales tienen la palabra, el Estado debe ir construyendo y consolidando enfoques multisectoriales en educación, ámbitos conjuntos de responsabilidad y debe ir compartiendo con los ministerios implicados, las municipalidades y la comunidad, inclusive, la buena marcha de la educación en cada territorio. El entramado político es un punto no menor de la política. Luego, hacer responsables a los alcaldes y a sus respectivos concejos, demandar calidad a la educación municipal y/o exigir que lo que se haga en educación se haga bien, no parece inadmisible.

Conjuntamente, urge reposicionar los planes comunales de educación y los recursos disponibles, no sólo como una obligación anual sino para generar y desplegar un programa destinado a creer, querer, desarrollar y defender una política de educación local.

\section{Referências}

ALVAREZ, E. Problemas para impulsar el mejoramiento educativo en el municipio: lecciones desde La Pintana. Santiago, Chile: CEPAL, 1995. (Serie Políticas Sociales; n. 11).

ARMIJO, M. Modernización administrativa y de la gestión pública en Chile. In: TOMASSINI, L.; ARMIJO M. (Comp.). Reforma y modernización del Estado. Santiago, Chile: Lom Ediciones, 2002.

BEYER, H. ¿Qué hacer con la Educación Pública? Estudios Públicos, Santiago, Chile, n. 114, p. 89-125, 2009.

CARNOY, M. Las políticas educacionales de Chile desde una perspectiva internacional. In: COX, C. (Ed.). Politicas educacionales en el cambio de siglo: la reforma del sistema escolar de Chile. Santiago, Chile: Editorial Universitaria, 2005. 
CHAPARRO, M. La gestión municipal en educación: la educación como gasto versus la educación como inversión. Santiago, Chile: CIDE, 1997. (Documentos, 2).

CHILE. Equidad y eficiencia en la transferencia para educación, salud e infraestructura a los municipios. Santiago, Chile: Universidad Alberto Hurtado, 2002a.

CHILE. Ministerio de Educación. Antecedentes sobre gestión escolar. In: FUENTES, R. (Coord.). Calidad en todas las escuelas y liceos: sistema de aseguramiento de la calidad de la gestión escolar. Santiago, Chile, 2005.

CHILE. Ministerio de Educación. Centro de Perfeccionamiento e Investigaciones Pedagógicas. Estilos de gestión y administración en educación municipalizada asociados con estrategias del CPEIP para formación continua de profesorado. Santiago, Chile: Universidad Católica Silva Henríquez, 2006. Disponible en: <http:// www.rmm.cl/usuarios/pponce/doc/

200704241330070.ucsh_informe_final_nov_2006.pdf> Acceso en: 23 mayo 2009.

CHILE. Ministerio de Educación. Estudio mejoramiento de la gestión y la calidad de la educación municipal. Santiago, Chile: POLITEIA, 2008a. Disponible en: $<$ http://w3app.mineduc.cl/mineduc/ded/documentos/

Estudio_POLITEIA_Resumen.pdf> Acceso en: 01 junio 2009.

CHILE. Ministerio de Educación. Fondo de apoyo al mejoramiento de la gestión municipal de educación: instrucciones para su operación. Santiago, Chile, 2007a. Disponible en:

<http://www.sudere.gov.cl/1510/articles-72475_recurso_4.pdf> Acceso en: 10 marzo 2009.

CHILE. Ministerio de Educación. Gestión municipal de la educación: diagnóstico y líneas de propuestas. Santiago, Chile: Asesorias para el Desarrollo, 2007b.

Disponible en:

<http://w3app.mineduc.cl/mineduc/ded/documentos/

Gestion_Municipal_de_la_Educacion.pdf> Acceso en: 13 junio 2007.

CHILE. Ministerio de Educación. Ley no 20.248 establece Ley de Subvención Preferencial. Leychile, Santiago, Chile, 2008b. Disponible en: <http://www.leychile.cl/ Navegar?idNorma=269001 ttipoVersion=0 . Acceso en: 25 agosto 2008.

CHILE. Ministerio de Educación. Ley n²0.370 establece la Ley General de Educación. Leychile, Santiago, Chile, 2009. Disponible en: <http://www.leychile.cl/ Navegar?idNorma=1006043\&tidParte=EtidVersion=2009-09-12> Acceso en: 14 septiembre 2009. 
CHILE. Ministerio del Interior. Subsecretaría de Desarrollo Regional y Administrativo. El Chile descentralizado que queremos: hacia un nuevo municipio. Santiago, Chile, 2002.

CHILE. Ministerio del Interior. Subsecretaria de Desarrollo Regional y Administrativo Sistema Nacional de Información Municipal. Santiago, Chile, 2007. Disponible en: <http://sinim.gov.cl>. Acceso en: 21 abr. 2009.

COMINETTI, R.; DI GROPELLO, E. La descentralización de la educación y la salud: un análisis comparativo de la experiencia latinoamericana. Santiago, Chile: CEPAL, 1998.

CORBETTA S. Territorio y educación: la escuela desde un enfoque de territorio en políticas públicas. In: LOPEZ, N. (Coord.). De relaciones, actores y territorios: hacia nuevas políticas entorno a la educación en América Latina. Buenos Aires, Argentina: IIPE - UNESCO, 2009.

CORNEJO, R. El experimento educativo chileno 20 años después: una mirada crítica a los logros y falencias del sistema escolar. Revista Electrónica Iberoamericana sobre Calidad, Eficacia y Cambio en Educación, Santiago, Chile, v. 4, n. 1, p. 118-129, 2006. Disponible en: <http://www.facso.uchile.cl>. Acceso en: 15 marzo 2007.

COX, C. Las políticas educacionales de Chile en las últimas dos décadas del siglo XX. In:___ (Ed.). Políticas educacionales en el cambio de siglo. La reforma del sistema escolar de Chile. Santiago, Chile: Editorial Universitaria, 2005.

DI GROPELLO, E. La descentralización de la educación y las relaciones de rendición de cuentas en los países latinoamericanos. Santiago, Chile: PREAL, 2004. (Documentos, 30).

DONOSO, S. La política de financiamiento de la educación básica en Chile (19802008): consecuencias y disyuntivas. Jornal de Políticas Educacionais, Curitiba, PR: NuPE, UFPR, v. 3, p. 17-29, 2008.

DONOSO, S. Reforma y política educacional en Chile 1990-2004: el neoliberalismo en crisis. Estudios Pedagógicos, Valdivia, Chile, v. 31, n. 1, p.113-135, 2005.

DONOSO, S.; SCHMAL, R. Los modelos de financiamiento de la educación pública en Chile y sus requerimientos de adecuación. Revista Electrónica de Investigación Educativa, Baja California, México, v. 2, n.4. 2002. Disponible en: <http:// redie.ens.uabc.mx/vol4no2/contenido-donoso.html>. Acceso en: 25 marzo 2004. 
EGAÑA, L.; MAGENDZO, A. El proceso de descentralización educativa bajo el régimen militar: descripción y análisis crítico. Santiago, Chile: PIIE, 1985. (Estudios, 41).

ESPINOZA, J.; MARCEL, M. Descentralización fiscal: el caso de Chile. Santiago, Chile: CEPAL, 1994.( Serie Política Fiscal, 57).

EYZAGUIRRE, N. et al. Hacia la economía del conocimiento: el camino para crecer con equidad en el largo plazo. Estudios Públicos, Santiago, Chile, n. 97, p. 5-57, 2005.

GARCIA-HUIDOBRO, J.; SOTOMAYOR, C. La centralidad de la escuela en la política educativa chilena de los años noventa. In: COX, C. (Ed.). Políticas educacionales en el cambio de siglo: la reforma del sistema escolar de Chile. Santiago, Chile: Editorial Universitaria, 2005.

GONZÁLEZ, P. Descentralización en educación: elementos a considerar en una política fiscal para América Latina. Santiago, Chile. 2005a. Disponible en: <http:// www.unesco.cl/port/sprensa/noticias/85.act?menu=/port/sprensa $>$. Acceso en: 20 sept. 2006.

GONZÁLEZ, P. Estructura institucional, recursos y gestión en el sistema escolar chileno. In: COX, C. (Ed.). Políticas educacionales en el cambio de siglo: la reforma del sistema escolar de Chile. Santiago, Chile: Editorial Universitaria, $2005 b$.

GYSLING, J. Reforma curricular: Itinerario de una transformación cultural. In: COX, C. (Ed.). Políticas educacionales en el cambio de siglo: la reforma del sistema escolar de Chile. Santiago, Chile: Editorial Universitaria, 2005.

HOPENHAYN, M. Gestión, organización y financiamiento del sistema educativo. Santiago, Chile: CEPAL, 1995. (Serie Políticas Sociales, v. 11).

LARRAÑAGA, 0. Descentralización de la educación en Chile: una evaluación económica. Estudios Públicos, Santiago, Chile, n. 60, p. 243-286, 1995.

LATORRE, C. et al. La municipalización de la educación: una mirada desde los administradores del sistema: un estudio a nivel comunal. Santiago, Chile: PIIE, 1991.

MIZALA, A.; ROMAGUERA, P. Regulación, incentivos y remuneraciones de los profesores en Chile. In: COX, C. (Ed.). Políticas educacionales en el cambio de siglo: la reforma del sistema escolar de Chile. Santiago, Chile: Editorial Universitaria, 2005. 
MONTT, P. et al. Hacia un sistema escolar descentralizado, sólido y fuerte: el diseño y las capacidades hacen la diferencia. Santiago, Chile: Ministerio de Educación, 2006. (Serie Bicentenario).

NICKSON, A. La descentralización política. In: CRESPO, I.; MARTÍNEZ, A. (Ed.). Política y gobierno en América Latina. Valencia, España: Tirant lo Blanch, 2005.

OCDE; CHILE. Revisión de políticas nacionales de educación: la educación superior en Chile. París: OCDE; Santiago, Chile: Ministerio de Educación, 2004.

PAVEZ, A. Municipios efectivos en educación. Santiago, Chile: Universidad de Chile. Facultad de Ciencias Físicas y Matemáticas, Departamento de Ingeniería Industrial, 2004. (Estudios de Caso, 81).

PIIE. Las transformaciones educacionales bajo el régimen militar. Santiago, Chile: Programa Interdisciplinario de Investigaciones en Educación, 1984. v. 1- 2.

PNUD. Desarrollo Humano en Chile: el Poder: ¿para qué y para quién? Santiago, Chile: Programa de las Naciones Unidas para el Desarrollo, 2004.

SERRANO, C.; FERNÁNDEZ, I.; PÁVEZ, A. Descentralización de la educación en Chile: balance y perspectivas. In: RACZYNSKY, D.; SERRANO, C. (Ed.). Descentralización. nudos críticos. Santiago, Chile: CIEPLAN, Asesorias para el Desarrollo, 2001.

SUBIRATS, J. Escuela y municipio: ¿Hacia unas nuevas políticas educativas locales? In: GAIRIN J. (Coord.). La descentralización educativa: ¿Una solución o un problema? Madrid, España: CISSPRAXIS, 2005.

WINKLER, D. Los retos de la financiación en la educación. In: FUNDACIÓN SANTILLANA (Ed.). Ponencias presentadas en la XIV Semana Monográfica de la Fundación Santillana. Madrid, España, 2000.

Recebido em: 21/12/2009

Aceito para publicação em: 21/03/2010 